\title{
Geothermal Power Project's Manageable Risks in Hungary
}

\author{
Aniko Toth ${ }^{1}$, Peter Szucs ${ }^{1,2}$, David Fenerty ${ }^{3}$ \\ ${ }^{1}$ Earth Science and Engineering Faculty, University of Miskolc, Miskolc, Hungary \\ ${ }^{2}$ MTA-ME Geoengineering Research Group, University of Miskolc, Miskolc, Hungary \\ ${ }^{3}$ Flatiron Tech Consulting, Inc., San Jose, the United States
}

Email address:

toth.aniko@uni-miskolc.hu (A. Toth)

\section{To cite this article:}

Aniko Toth, Peter Szucs, David Fenerty. Geothermal Power Project's Manageable Risks in Hungary. Earth Sciences. Vol. 10, No. 4, 2021, pp. 170-179. doi: 10.11648/j.earth.20211004.14

Received: February 3, 2021; Accepted: August 2, 2021; Published: August 30, 2021

\begin{abstract}
There are many compelling arguments for using geothermal energy in Hungary. One of the most important is that the country could thereby exploit its abundant, relatively untapped network of geothermal reservoirs. These are considerably warmer and closer to the surface than in most of Europe. In the foreseeable future, Hungary's geothermal resources can satisfy the conditions required for efficient energy production. The tremendous amount of energy stored in our geothermal reservoirs could satisfy much of the country's long-term energy demand. Every geothermal project is designed to fulfill its project objectives by meeting time, budget, technical, and legal/regulatory provisions. Geothermal development is necessarily exposed to risks of varying degrees throughout its development, something which distinguishes geothermal from other kinds of renewable-energy projects. These risks most often concern the availability, amount, suitability, sustainability and use-potential of the geothermal resource, but may also include market, financing, commercial and macro-economic risks. This article describes the geological background and geothermal potential in Hungary. Hungary's current geothermal production remains at a low level, given its proven capacity. Although Hungary lacks an overarching national plan for specifically exploiting its geothermal resources, the 2018 National Smart Specialization Strategy (S3) highlights the promotion of clean and renewable energies. Geothermal clearly fits into this scheme, as S3 is designed to include renewables, nuclear energy and increased energy efficiency in conventional energy production. Furthermore, in 2020 the Hungarian Energy and Public Utility Regulatory Authority (HEA) compiled a plan to promote the greater use of geothermal energy. Based on the Hungarian government's geothermal investment support scheme, the authors have presented a risk-based assessment of Hungary's geothermal development possibilities, differentiated in terms of low, medium and high risk levels.
\end{abstract}

Keywords: Geothermal Risk, Uncertainty, Investment, Abandoned Hydrocarbon Wells, Support, Hungary, EU

\section{Introduction}

All geothermal projects aim to generate inexpensive power for consumers and yield a profit for investors, while holding down operational and maintenance costs. To meet these goals, there has to be a demand for power, the resource should be suitable, and the resource's exploitation must be sustainable. Once legal/environmental questions are resolved, a proven, economical technology can be developed to exploit the resource. At that point, the necessary investors, lenders, customers, and technical experts must agree to get involved. This would also minimize project risk for investors [12].
Although national governments use many policy and regulatory instruments to smooth the path for renewable energy production, the high-risk and significant up-front capital required for geothermal power development makes it a special case in the renewable-energy palette: until the first borehole is drilled into a geothermal reservoir, developers cannot know the exact parameters of the planned geothermal project [11]. As drilling continues, the new information gathered helps reduces risk and attract external capital. In any case, time-risk reduction for geothermal projects works best as a component of coordinated plans which recognize the project's particular needs and conditions [14]. 


\section{Geological Background and Geothermal Potential in Hungary}

The outstanding geothermal potential of the Pannonian Basin is manifested in an elevated heat flow density (50-130 $\mathrm{mW} / \mathrm{m}^{2}$, with a mean value of $90-100 \mathrm{~mW} / \mathrm{m}^{2}$ ) and a geothermal gradient of about $45 / \mathrm{km}$ [5]. This is a result of the basin's Early-Middle Miocene formation, when the lithosphere stretched and became thinner (the crust is "only" $22-26 \mathrm{~km}$ thick), and the hot asthenosphere got closer to the surface [3].

Hungary is geologically and hydrogeologically diverse, and almost all its interesting features are close to each other. These unique natural variations are due to the relative thinness of the Earth's crust under the Pannonian basin and the tectonic compression which caused higher pore pressure in deeper reservoirs.

The River Basin Management plan of Hungary identifies 185 groundwater bodies, with 40 officially registered as transboundary aquifers. In fact, almost half of all groundwater bodies (i.e., mare than 80) cross national borders, so that other nations could in principle affect the quantity and quality of Hungary's groundwater resources. Of the 185 groundwater bodies, 37 were classified as poor, and 20 as good, but at risk of deteriorating. Most poor water bodies were shallow porous or porous (27 and 9, respectively). None of the porous thermal water bodies and only a single thermal karst water body were classified as poor.

Figure 1 shows the porous thermal groundwater bodies. Geothermal investors face few risks as far as these sedimentary thermal groundwater bodies are concerned, since new wells in these formations are usually successful. The situation is the opposite for the fractured thermal aquifers, where it is very difficult to reach and find the productive fractures and fault zones. Figure 2 describes Hungary's karst and thermal karst groundwater bodies in greater detail.

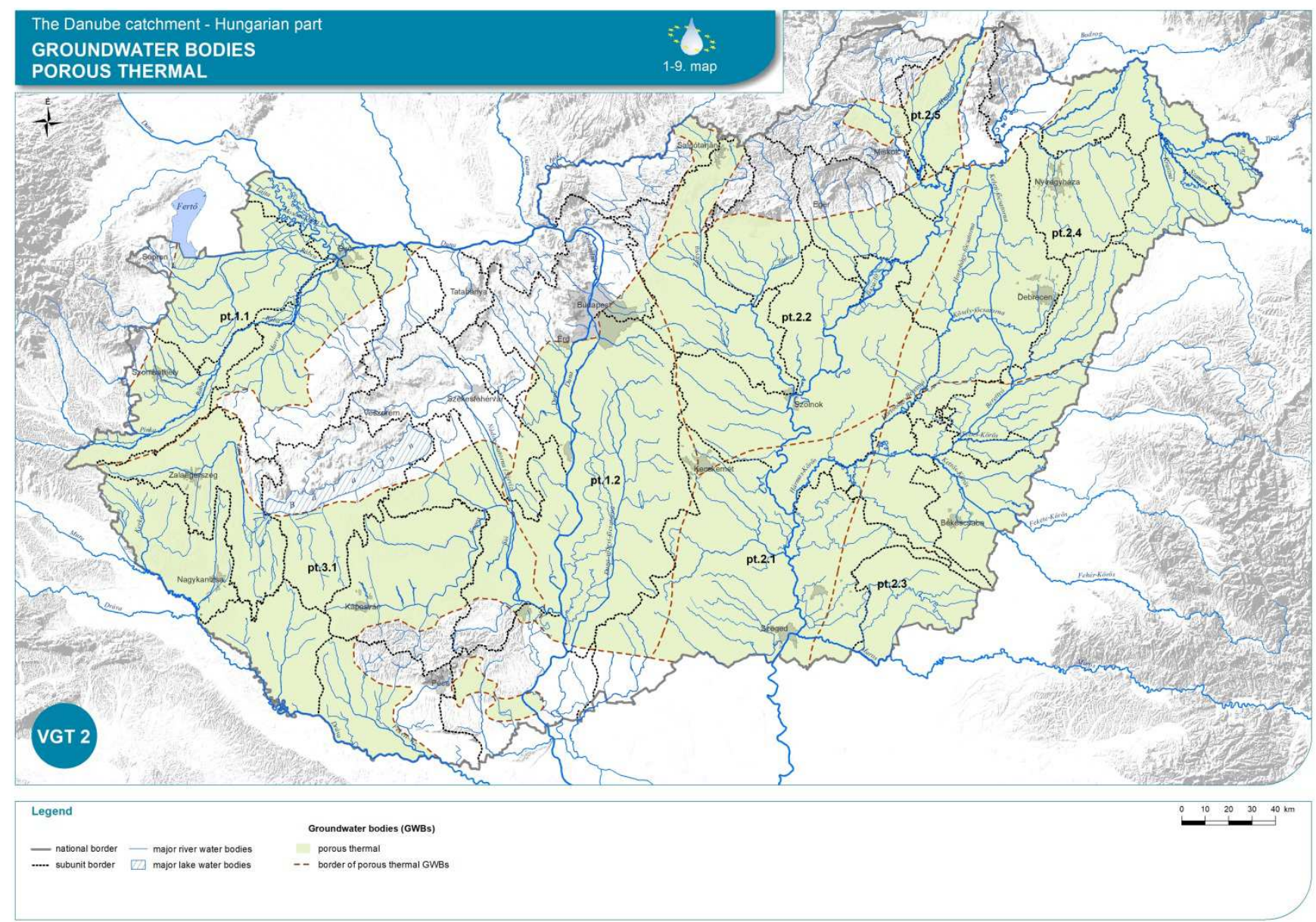

Figure 1. Porous thermal groundwater bodies in Hungary (source: www.vizeink.hu, Hungarian Water Management Plan).

Hydrogeology plays a major role in increasing the use of geothermal energy sources in Hungary. Hungary's excellent geothermal potential, its different hydrogeothermal systems and its thermal water utilization options have been described in numerous studies over the past years [4]. The country's heterogeneous geological and hydrogeological situation indicate that the scope of current geothermal methods could be extended [1].

In the most favored parts of Hungary's southern Great Plains, medium enthalpy heat utilization units could be installed almost anywhere. It is clear, however, that thermal water production rates are unsustainable at several locations, 
as shown by continuously decreasing water levels. For that reason, reinjection systems were made a legal requirement, even though this was not always financially beneficial to all stakeholders.

There are two major types of geothermal reservoirs. The first is the so called basement reservoir, associated with the main tectonic zones and the uppermost weathered-karstified zones of the deeply buried Palaeozoic-Mesozoic carbonates and crystalline rocks, forming the basement of the Pannonian Basin. At a depth of $2000 \mathrm{~m}$ or more, where temperature can exceed $100-120{ }^{\circ} \mathrm{C}$, these zones have increased secondary porosity and form favorable geothermal reservoirs. The second type is the basin-fill reservoir. These reservoirs lie within the several-thousand meter thick multi-layered, porous
Upper Miocene-Pliocene "Pannonian" basin fill sequence, where the main geothermal aquifers are associated with regionally extended $100-300 \mathrm{~m}$ thick sandy units. They are found at a depth interval of ca. 700-2000 $\mathrm{m}$ in the basin's interior, where the temperature ranges from 60 to $90{ }^{\circ} \mathrm{C}$. These reservoirs have an almost uniform hydrostatic pressure.

Some high-enthalpy reservoirs also exist in Hungary. They are related to deep-lying (3500-4000 m), overpressured fractured rocks (dolomites). In addition, deeply-buried granitoid rocks with high in-situ rock temperatures $\left(\geq 200^{\circ} \mathrm{C}\right)$ and favorable seismo-tectonic settings (extensional regime, low level of natural seismicity) provide promising settings for future EGS project developments [3].

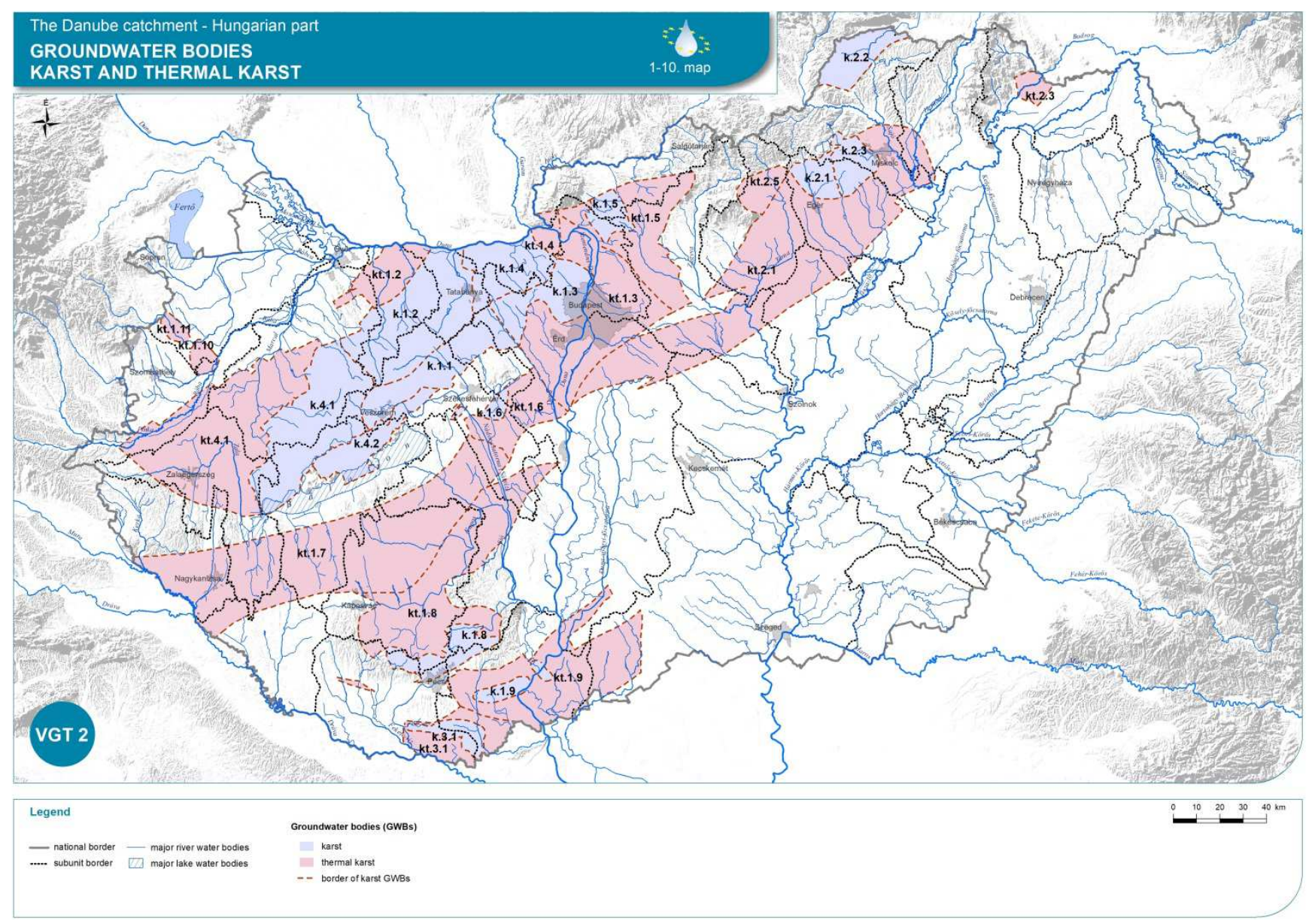

Figure 2. Karst and thermal karst groundwater bodies in Hungary (source: www.vizeink.hu).

\section{Hungary's Current Geothermal Situation}

Hungary has a long history of geothermal energy use, with a greater installed geothermal capacity for heating and cooling than almost anywhere in Europe. Although much of the installed geothermal capacity dates back to the second half of the 20th Century, many projects have been commissioned since 2010, highlighting the current dynamism of the Hungarian geothermal sector. At present, projects are largely owned or managed by local authorities, notably through municipalities or public utilities.

For the larger thermal water users (e.g., municipal public works), the financial benefit remains even if the added cost of reinjection is considered. The protection of the natural groundwater systems must of course be given higher priority than the protection of local financial interests. In the past, cooled waters which often had very high salt content caused severe environmental problems as they flowed out of Hungary through our major rivers. From a water 
management perspective, however, it is not inexcusable that of the app. 50 million $\mathrm{m}^{3} /$ year produced for energy use, only about 2 million $\mathrm{m}^{3}$ is reinjected.

In 2019, more than 900 active thermal water wells produced about 90 million $\mathrm{m}^{3}$ of thermal water in Hungary, representing $1023.7 \mathrm{MWt}$ or $10,701 \mathrm{TJ} / \mathrm{y}$. The agriculture sector is still a key player in direct use, especially in SE Hungary, where heating greenhouses and plastic-tents is traditional. These account for $358 \mathrm{MWth}$ installed capacity and $2,891 \mathrm{TJ} / \mathrm{yr}$ production.

Geothermal district-heating and thermal-water heating cascade systems represent a major part of Hungary's direct use, available in 23 towns representing about 223,4 $\mathrm{MW}_{\text {th }}$ installed capacity and 2,288 $\mathrm{TJ} / \mathrm{y}$ annual production. Major new projects have been established in Györ and Szeged. Individual space heating (mostly associated with spas) is available in nearly 40 locations, representing an estimated installed capacity of about 77,2 $\mathrm{MW}_{\text {th }}$ and $299 \mathrm{TJ} / \mathrm{yr}$ production [6].

The Hungarian geothermal sector is dynamic, with about 12 ongoing projects for heat production and two ongoing projects for electricity production. Current ongoing projects are set to double installed heat production capacity, a good foundation upon which to build towards new climate and energy objectives planned for 2030 .

\section{Hungary's Geothermal Investment Projects and Risk Mitigation Planning}

Hungary does not have a specific energy technology RDI strategy. However, the National Smart Specialization Strategy (S3), highlights the promotion of clean and renewable energies, including renewables and bioenergy, nuclear energy and energy efficiency, as one of its sectorial priorities.

In 2020 the Hungarian Energy and Public Utility Regulatory Authority (HEA) compiled a plan to promote the greater use of geothermal energy. This plan is based on many completed and on-going projects such as Geothermal Budapest [6], the GEORISK Project [7], the GEOENVI Project [8] and the Hungarian Geothermal Atlas [9]. The primary goal is to produce geothermal energy within a given district heating system, to a greater extent than now occurs. This plan takes into account the entire value chain of geothermal energy, with incentives for all stakeholders (producers, service providers and users). Its approach is integrated, as its use of different forms of cooperative and interdependent incentive structures. This program plan is based on three pillars: Geothermal Risk Guarantee Fund, Geothermal Investment Support Scheme and District Heating Premium System.

\subsection{Geothermal Risk Guarantee Fund}

The Geothermal Risk Guarantee Fund operates within professional and financial constraints, addressing the technical and financial uncertainty related to geothermal district heating facility construction. The fund would be supported by a state guarantee and member payments.

\subsection{Geothermal Investment Support Scheme}

The Geothermal Investment Support Scheme would be a grant scheme specifically linked to geothermal heat production development and, where geothermal heat production already exists, to investments that increase geothermal use. All actors in the geothermal value chain would be potential recipients, including end-users. This type of subsidy aligns with the current structure of district-heating price regulation, so there would be no recognized profit or depreciation after the subsidy. Support would come from EU funds.

This scheme is designed to address risk reduction and management during exploration, drilling, construction and eventual operation.

\subsection{District Heating Premium System}

The regulation of district heating prices and district heating subsidies would be supplemented by a new type of subsidy, the so-called district heating provider premium, while maintaining its current methodology. This subsidy requires the district heating provider to make concrete efforts to increase the provider system's share of geothermal energy, and thereby qualify for additional subsidies per GJ. The source of the premium would be money paid into the district heating fund. This support distinguishes between two cases:

a. where geothermal district heat production does not yet exist, although potentially feasible, the level of support is conditional on the share provided by geothermal energy rising to between $25 \%-100 \%$, for a minimum of $20 \mathrm{Ft} / \mathrm{GJ}$ and a maximum of $300 \mathrm{Ft} / \mathrm{GJ}$;

b. where geothermal district heating already exists but can be increased, the level of support is conditional on the share of geothermal energy rising to between $55 \%$ $100 \%$, for a minimum of $20 \mathrm{Ft} / \mathrm{GJ}$ and a maximum of $300 \mathrm{Ft} / \mathrm{GJ}$.

\subsection{National Energy Action Plan}

The 1345/2018. (VII. 26.) Governmental Decision on the Action Plan of the Utilization and Management of Energetic Mineral Resources is an important piece of recent legislation, which set up concrete tasks with deadlines and responsible ministries for helping develop deep geothermal energy. It states that during the development of national RDI programs and funding schemes, geothermal power production without water abstraction and reinjection technologies should be treated as priorities. Crucially, it also addresses geothermal risk mitigation by calling on the Minister for Innovation and Technology and the Minister for Finances to make a joint proposal to introduce financial tools for the mitigation of high upfront risks for geothermal projects (i.e., a risk insurance scheme) by June 2019 .

Since the introduction of the concessional system in 2010 (obligatory for the exploration and exploitation of geothermal 
energy at a depth below 2,500 $\mathrm{m}$, the typical depth range for power production and CHP projects), a preliminary complex vulnerability and impact assessment (CVIA) has been prepared for over 20 potential geothermal areas, as a prerequisite for concessional tendering. Figure 3 shows the government-assigned concession zones, outlined in red.

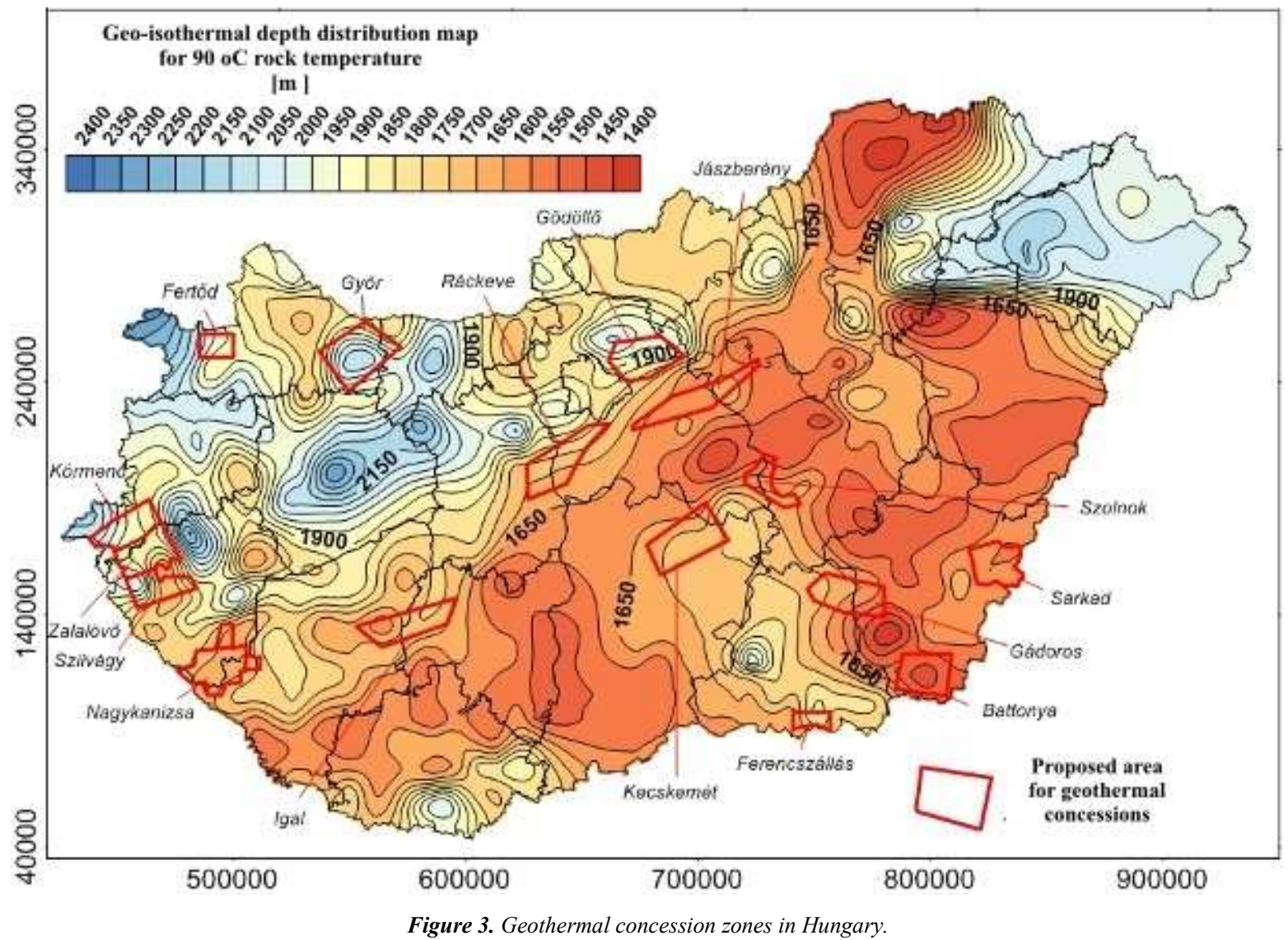

The aim of the CVIA is to provide a general overview of the future concessional area (geology, hydrogeology, geothermal conditions, etc.) and to determine those factors and areas within the planned concessional block, where future "mining activity" cannot be performed due to several restrictions (environmental- and nature protection, water management, protection of cultural heritage, agriculture, national defense, land-use, etc.).

The government's approach takes into account the fact that resource risk (e.g., unsuccessfully drilling for usable thermal water) is a major barrier to geothermal development in Hungary and worldwide, and something that can stall geothermal development in its initial stages. The high risks typically encountered in a new geothermal field make it hard to raise the risk capital needed to fund early drilling, so many geothermal developments are undertaken by government or government-supported entities, including national oil companies and state-owned enterprises [13]. Although geothermal development has expanded when qualified entities and sufficient capacity exist in a country, many governments have neither the financial capacity nor the technical expertise to promote such expansion of their geothermal resources on a large scale. In such cases, other ways must be found to attract the required private capital and expertise.

\section{Risk-Based Assessment of Hungary's Geothermal Development Possibilities}

In the business world, risk management is thought of as the process of identification, evaluation, and prioritization of risks followed by coordinated and economical application of resources to minimize, monitor, and control the probability or impact of unfortunate events or to maximize the realization of opportunities [15].

Table 1. Risk categories [2].

\begin{tabular}{lll}
\hline Category & Risk factor & Description \\
\hline Very high & $>0.85$ & More factors which might increase risk significantly \\
High & $0.50-0.85$ & One or more factors might increase risk significantly \\
Average & 0.5 & No preponderance of significant risk factors \\
Low & $0.15-0.50$ & All factors are positive, minimizing overall risk \\
Very low & $<0.15$ & Sufficient proof to rule out risk almost entirely \\
\hline
\end{tabular}


As geothermal energy production is currently limited to heat production, the following geo-isothermic map (Figure 4) is the easiest way to visualize Hungary's geothermal situation. The darkest red (or darkest in $\mathrm{B} / \mathrm{W}$ ) show where $90^{\circ} \mathrm{C}$ heat is closest to the surface, the darkest blue (or lightest in $\mathrm{B} / \mathrm{W}$ ) show where $90^{\circ} \mathrm{C}$ heat is farthest away from the surface. The main heat-producing regions are marked with a dot, surrounded by a rectangle.

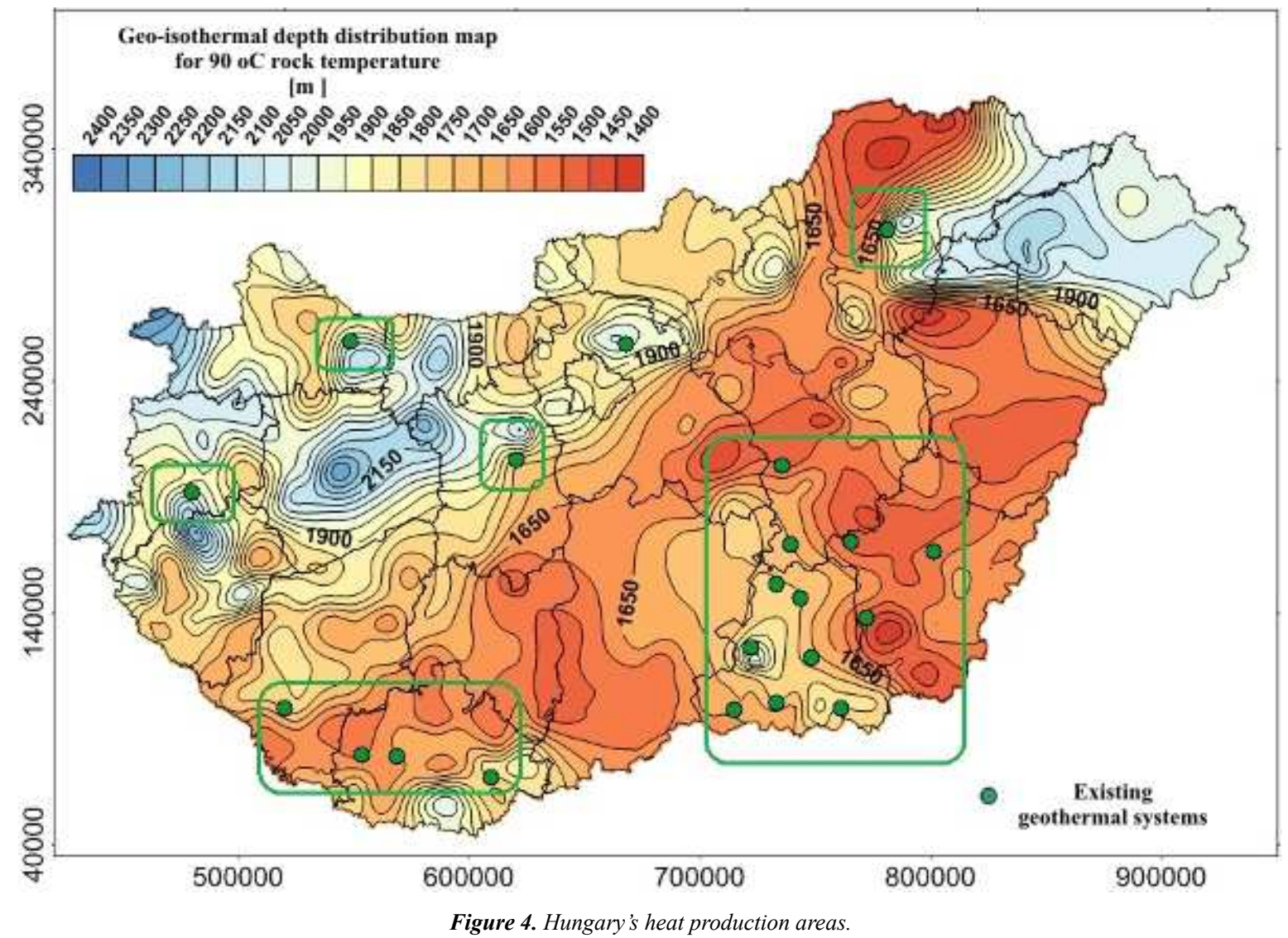

Currently and for more than fifty years, thermal energy extraction/production has been concentrated in SE Hungary, around the cities of Szeged, Szentes, Hódmezővásárhely, Gyula, Szarvas and Gyomaendrőd. Because this region's geothermal resources were first revealed while drilling for oil and gas, geothermal developers can exploit the advantages that so often accompany intensive hydrocarbon exploration: abundant geological documentation; well-designed well structures; the relative proximity of potential well pairs or triplets, and; half a century of practical experience and specialized technical expertise.

For this article, we have considered the low, average and high risk categories. In our opinion, the very low risk choice means doing practically nothing, and the very high risk category would require that Hungary take on unrealistically high costs and use unproven technologies.

\subsection{Low-Risk Case Scenario - Maintenance of Major Existing Production Facilities}

The lowest-risk strategy would mean sticking to the current model used by Pannergy and the remaining smaller, undercapitalized geothermal producers, which means continuing to maintain district- and greenhouse-heating projects, without attempting to significantly widen those projects' scope or increase their efficiency. Currently, Pannergy Plc. is the most significant player in the domestic market. Based on the limited data available for 2018 (thermal heat producers were not completely clear about how much revenue and profit came from purely geothermal heat production), we estimate the total domestic GeoDH market at around USD 20-25 million. More than $60 \%$ of that amount was produced by Pannergy Plc. (based on Pannergy production heat data - not its sales data!), which company produced about 1,404 TJ on a consolidated level in 2018 .

\subsection{Average-Level Risk Scenario - Domestic Project Development}

In this more ambitious scenario, project developments would be implemented on several levels by several companies or agencies, with the aim of expanding the existing geothermal heat generation systems while more efficiently exploiting their 'cascade' opportunities, i.e., using heat that is currently wasted, for a variety of uses at different temperature ranges.

In Figure 5, green dots show existing geothermal sites and black circles show potential development zones. 


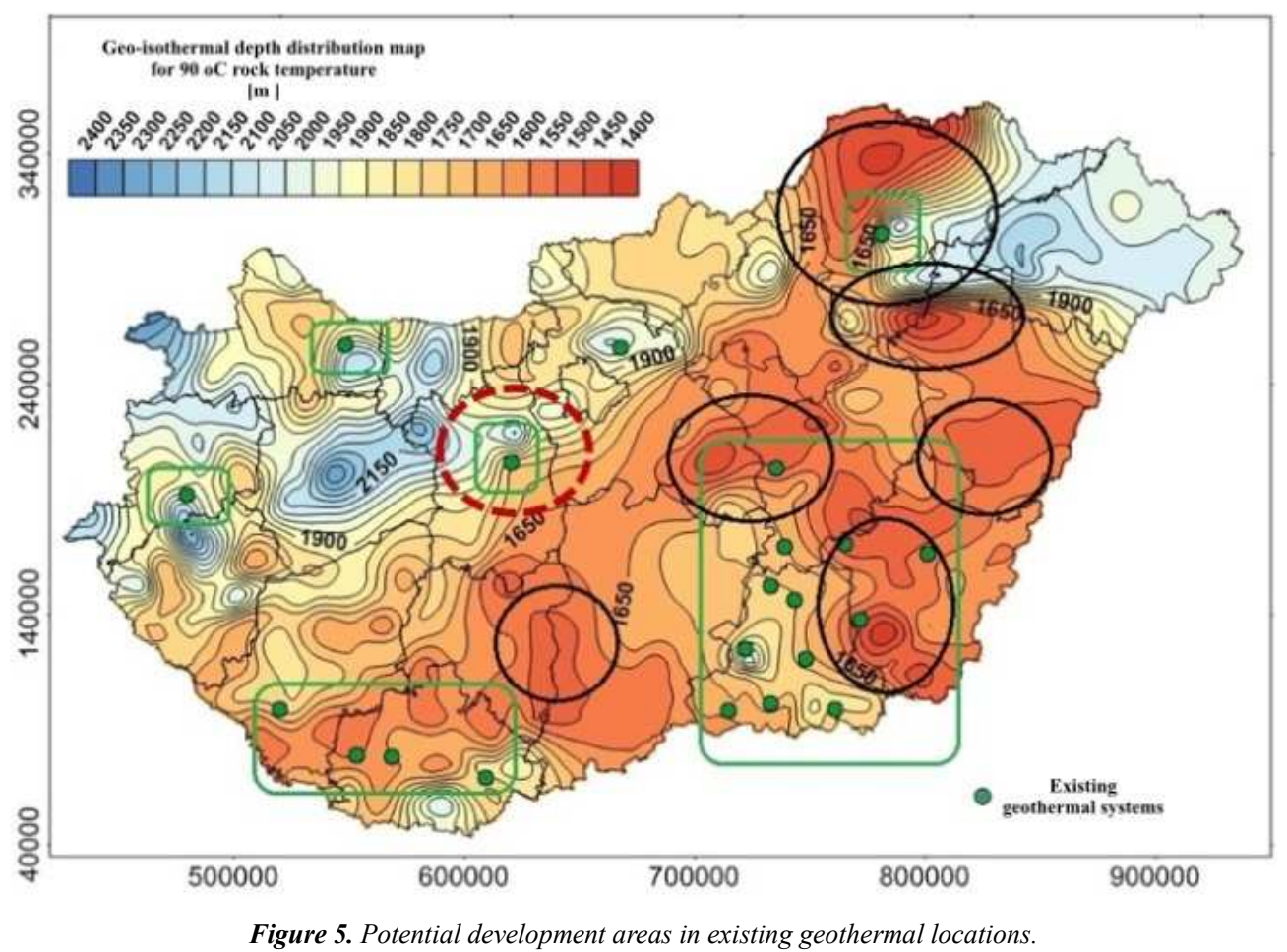

There are three main possibilities. The first is to develop existing systems by creating a higher thermal ladder and/or cascade system in a place such as the Mályi - Kistokaj Miskolc region in NE Hungary. There, the current $25-30^{\circ} \mathrm{C}$ heat step can be increased by an additional $15-25^{\circ} \mathrm{C}$ merely by installing additional heat exchange equipment. This would more than double the district heating capacity for Miskolc (population approx. 160,000), boosting the current 50 MW heating capacity by an additional 70-90 MWt. Installing heat pumps would provide an additional $15-25$ MWt of energy for greenhouses, wood dryers or crop dryers.

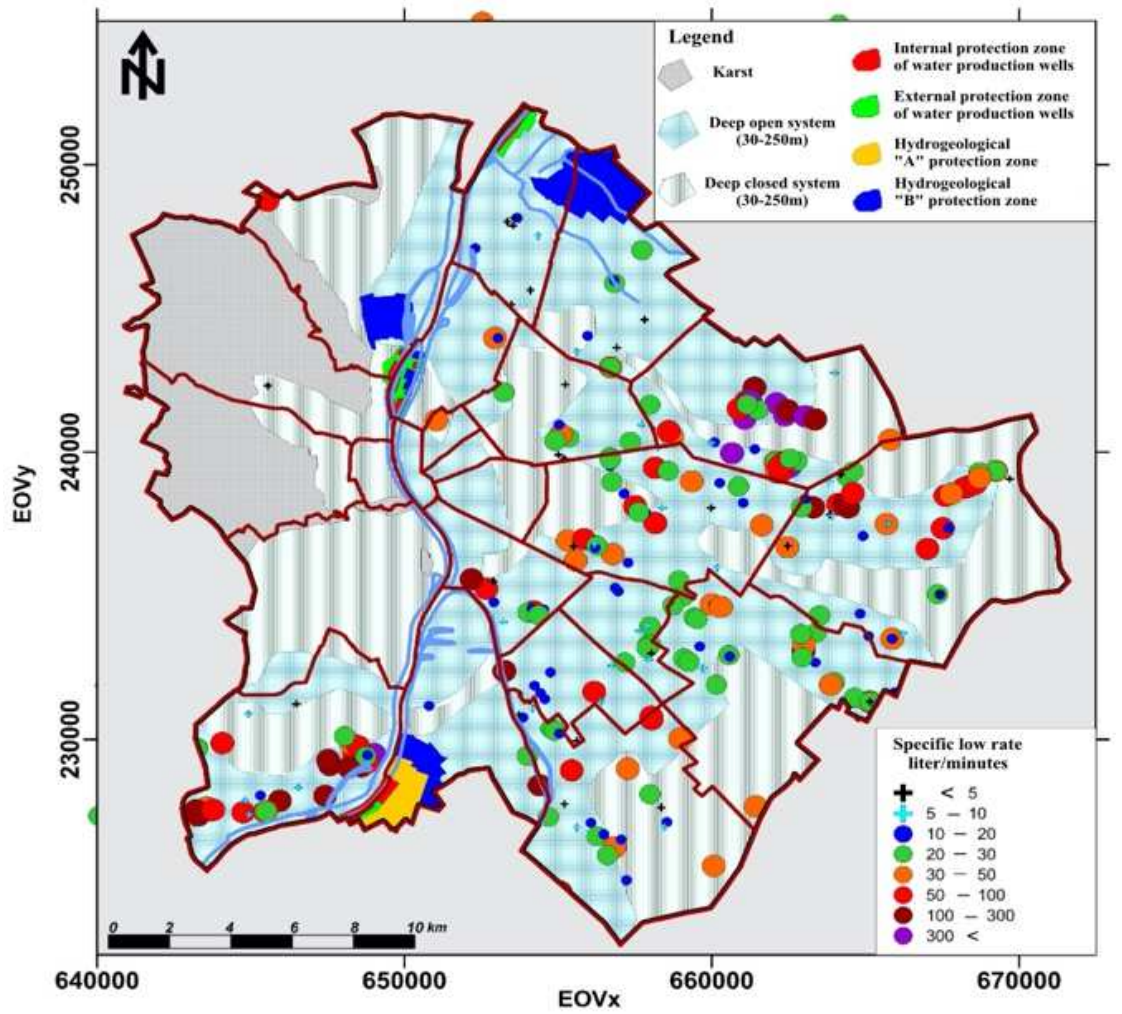

Figure 6. Budapest's existing geothermal wells. 
The second possibility would involve constructing entirely new geothermal thermal power plants in the catchment area of the largest heat markets, to take advantage of the national government's recently published goal of replacing 30-50\% of Budapest's fossil-based district heating with geothermal heat [9]. To this end, greater
Budapest would require at least three geothermal-based heat supplies, optimally located in Kelenföld, Kispest and Újpest. Figure 6 shows Budapest's existing thermal wells, along with their respective flow rates; Figure 7 shows where new geothermal power plants could be built, based on local geology and thermal-energy demand.

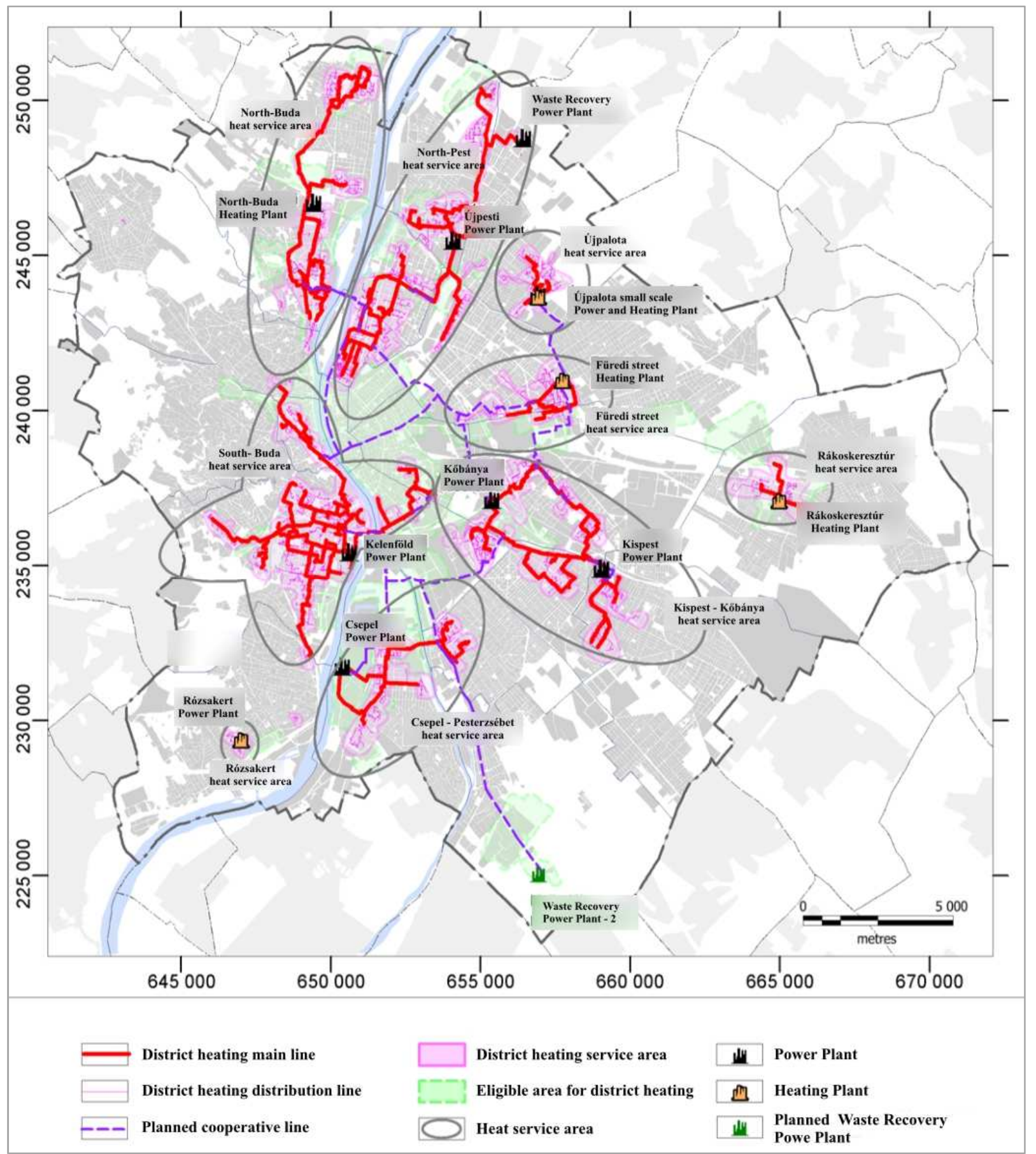

Figure 7. Possible new power plants.

The third and most intriguing possibility would involve converting the area's many abandoned hydrocarbon wells into geothermal wells, where appropriate [10]. Since any geothermal project's largest capex outlay is for well drilling and design, this approach could be much more economical, as most of those wells are still in good condition and have been abundantly documented. The abandoned hydrocarbonwell allocations are shown in Figure 8. 


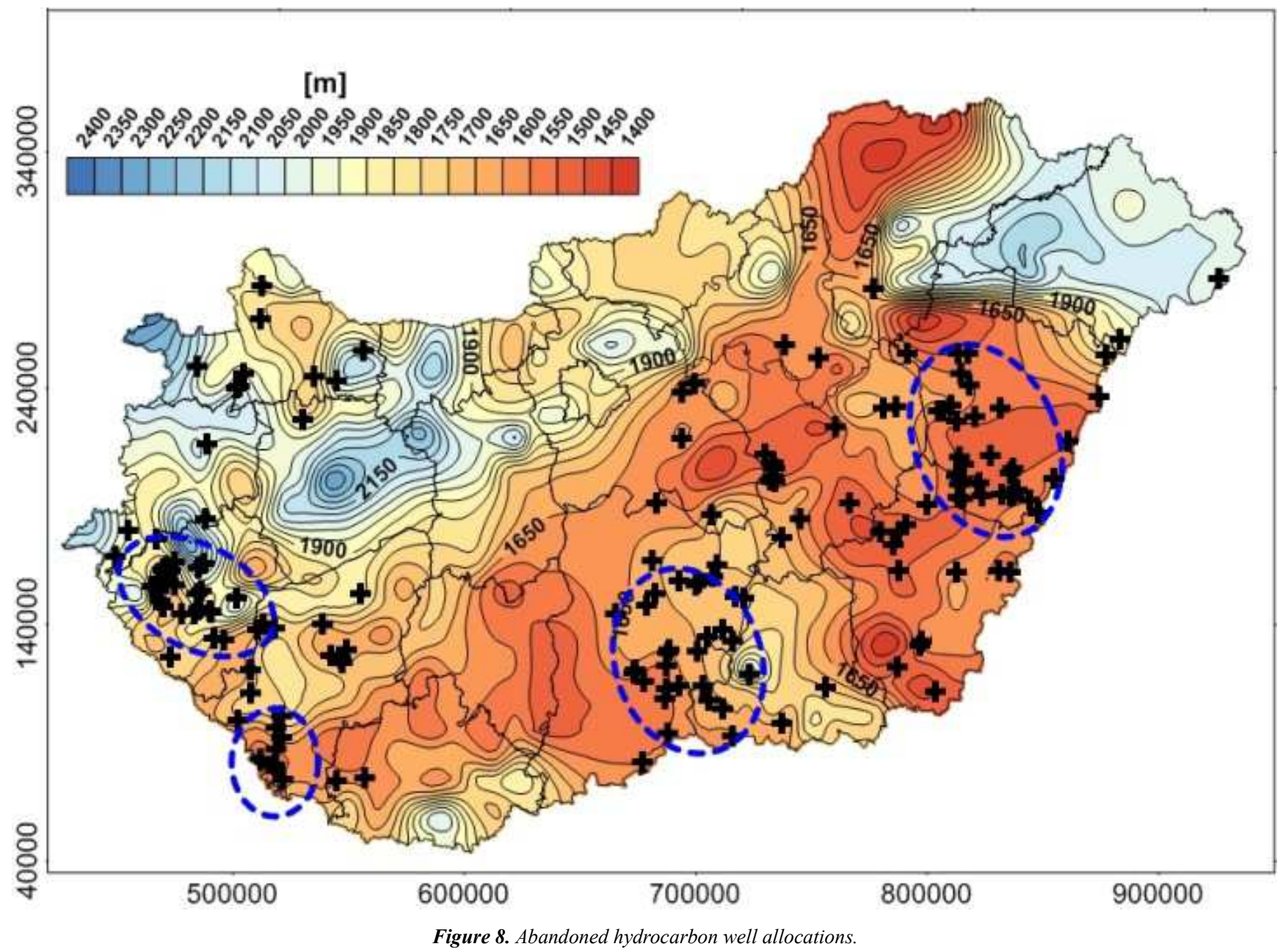

Despite the promising potential for geothermal to provide Hungary with more energy, progress has been agonizingly slow. This is shown most clearly by the example of Tura, the country's first geothermal power plant, completed in 2018. As of 2021, the Tura power plant is theoretically capable of producing about $1 \mathrm{MW}_{\mathrm{e}}$ of Hungary's installed capacity - but that $1 \mathrm{MW}_{\mathrm{e}}$ would still be used mostly to run the plant itself. In 2020 a new geothermal well was drilled very near the existing production well, with the aim of raising the mass flow rate and efficiency of the Tura power plant. This development involved significant new expense in terms of drilling the new well. It also made the project more uncertain by interrupting production, changing the reservoir's physical conditions, and introducing the new factor of unpredictable water production from the new well (i.e., outflow water pressure and temperature). For those reasons, the entire Tura project could be on the verge of moving from average- to high-risk.

\subsection{High Risk Scenario}

The high-risk scenario would dispense with the previously mentioned low- and medium-risk possibilities, and instead attempt to produce electricity from new or existing geothermal plants. This approach is naturally tempting, as it promises to give Hungary much greater energy independence. Its drawback is that no existing technology has proven that it can economically produce electricity from Hungary's abundant but not extremely hot thermal water sources. Unlike such countries as Iceland, Indonesia and New Zealand, Hungary does not sit on a tectonic-rift that can deliver magma-heated steam to electricity-generating turbines at the surface. Deep-drilling pilot projects designed to use EGS technology for electricity production have likewise failed to prove their economic viability, although they have yielded scientifically useful information.

\subsection{Very High Risk Scenario}

In 2016, the European Commission in Brussels awarded the EGS Hungary consortium (co-owned by EU-FIRE and Mannvit) roughly 39.3 million $€$ to develop a 116 million $€$ project plan entitled "South Hungarian Power Plant with an Enhanced Geothermal System, (SHEGSDP)". With its key objective that of providing green and sustainable electricity production, EGS Hungary agreed to find an EGS reservoir site in the South of Hungary (Battonya), construct surface facilities, drill geothermal wells, use those wells to stimulate the surrounding geothermal resource, and ultimately produce 11.8 MW of total electric power and 74,000 MWh of 
generated electricity per year. This project is currently far behind schedule, perhaps because of its high risk factor.

\section{Conclusion}

The best way for Hungary to develop its geothermal resources is to adopt a "low-hanging fruit" approach, i.e., the first possibility described under the Medium Risks Scenario simply improving the existing district-heating systems by adding heat-pumps, and exploiting the resulting cascade-use opportunities to develop nearby local agricultural sectors, which have long been the heart of Hungary's regional economy. This could improve on the Tura plant's minimal electricity production by allowing it to also provide thermal energy to neighbors.

These limited-scale projects would require relatively only moderate investment, and their success would significantly boost areas hard hit by recent economic downturns. Improving existing district-heating projects and the power plant is a modest goal, but if successful, it would then be easier to attract the investment necessary for the more ambitious second and third possibilities: creating new geothermal district heating projects for the underserved parts of Budapest, and re-purposing the thousands of abandoned hydrocarbon wells scattered across geothermally promising regions of Hungary.

Assessed according to the geothermal industry's international standards, Hungary's EGS projects have a very high risk -- about a Technology Readiness Level 6-7 in terms of manageable risk for Hungarian geothermal projects. Such EGS projects are undeniably important for Hungarian academic-level geothermal research. They would only be economically useful, however, in the distant future.

\section{Acknowledgements}

The cross-cutting research was conducted at the University of Miskolc as part of the "More efficient exploitation and use of subsurface resources" project implemented in the framework of the Thematic Excellence Program funded by the Ministry of Innovation and Technology of Hungary (Grant Contract reg. nr.: NKFIH-846-8/2019), and within the subsequent "Developments aimed at increasing social benefits deriving from more efficient exploitation and utilization of domestic subsurface natural resources" project supported by the Ministry of Innovation and Technology from the National Research, Development and Innovation Fund according to the Grant Contract issued by the National Research, Development and Innovation Office (Grant Contract reg. nr.: TKP-17-1/PALY-2020).

The research was conducted at the University of Miskolc as part of the "Developments aimed at increasing social benefits deriving from more efficient exploitation and utilization of domestic subsurface natural resources" project supported by the Ministry of Innovation and Technology from the National Research, Development and Innovation Fund according to the Grant Contract issued by the National
Research, Development and Innovation Office (Grant Contract reg. nr.: TKP-17-1/PALY-2020).

\section{References}

[1] Buday, T., Szűcs, P., Kozák, M., Püspöki, Z., McIntosh, R. W., Bódi, E., Bálint, B. and K. Bulátkó, 2015. Sustainability aspects of thermal water production in the region of Hajdúszoboszló-Debrecen, Hungary. Environmental Earth Sciences, 73 (7), Paper 3983-1, 11 p.

[2] Otis, R. M., Schneidermann, N., 1997. A Process for Evaluating Exploration Prospects, AAPG Bulletin, Vol. 81, 1-7.

[3] Nador, A., Kujbus, A., and Tóth, A. N., 2019. Geothermal energy use, country update for Hungary. Proceedings, European Geothermal Congress 2019, Den Haag, The Netherlands.

[4] Szűcs P., Madarász T., 2013: Hydrogeology int he Carpathian basin - how to proceed? European Geologist, No. 35, May 2013, ISSN: 1028-267X, pp. 17-20.

[5] Toth, A., Bobok E., 2017. Flow and Heat Transfer in Geothermal Systems, Elsevier, Amsterdam, ISBN 978-0-12800277-3, pp 3-4.

[6] Toth, A., 2020: Hungarian Country Update Report, World Geothermal Congress 2020, Reykjavik, Iceland.

[7] GEORISK PROJECT, 2018. https://www.georisk-project.eu

[8] GEOENVI PROJECT, 2018. https://www.geoenvi.eu

[9] Toth, A. 20217: Creating a Geothermal Atlas of Hungary, PROCEEDINGS. 42nd Workshop on Geothermal Reservoir Engineering Stanford University. Stanford. California. SGPTR-212.

[10] Toth A., Szucs, P., Pap, J., Nyikos, A. and Fenerty, D., 2018: Converting Abandoned Hungarian Oil and Gas wells into Geothermal Sources, PROCEEDINGS, 43rd Workshop on Geothermal Reservoir Engineering Stanford University, Stanford, California, SGP-TR-213.

[11] World Bank 2016: Comparative Analysis of Approaches to Geothermal Resource Risk Mitigation, Report Number 105172, https:/documents1.worldbank.org/curated/en/6211314681805343 69/pdf/105172-ESM-P144569-PUBLIC-FINAL-ESMAPGeoRiskMitigation-KS024-16-web.pdf

[12] Paul K. Ngugi, 2014. Risk and Risk Mitigation in Geothermal Development, Presented at "Short Course VI on Utilization of Low- and Medium-Enthalpy Geothermal Resources and Financial Aspects of Utilization", organized by UNU-GTP and LaGeo, in Santa Tecla, El Salvador.

[13] European Commission 2020: Hungary's National Energy Efficiency Action Plan until 2020, Mandatory reporting under Article 24 (2) of Directive 2012/27/EU of the European Parliament and of the Council on energy efficiency.

[14] Robertson-Tait, A., Jayawardena, M., Sanyal, S., Berman, L. and Huttrer, G. 2015: An Evaluation of Risk Mitigation Approaches for Geothermal Development, Proceedings World Geothermal Congress 2015, Melbourne, Australia.

[15] Tester, J. W., Anderson, B. J., Batchelor, A. S., Blackwell, D. D., DiPippo, R., Drake, E. M. Veatch, R. W., 2016. The Future of Geothermal Energy. Idaho National Laboratory, U.S. Department of Energy. 